\title{
Conducting controlled human infection model studies in India is an ethical obligation
}

\section{SAUMIL Y DHOLAKIA}

\begin{abstract}
Weighing competing obligations and achieving the "greatest balance" of right over wrong guides an individual, an agency or a country in determining what ought to be done in an ethically challenging situation. Conducting controlled human infection model (CHIM) studies in India is one such situation. The ethical challenge in conducting a CHIM study lies in completing the difficult task of introducing standardised, attenuated strains of micro-organisms into normal healthy volunteers, at the same time ensuring the safety of these healthy individuals from potential and completely informed risks in a fashion that is transparent and accountable. The bar is further raised against the background of already fragile public confidence in biomedical research in India; especially when "deliberate" introduction of microbial agents into healthy individuals is involved, with the larger altruistic objective of gain to society as a whole.
\end{abstract}

This paper discusses the uses of CHIM studies with respect to the larger scientific Indian research enterprise of the 21st century. It further explores etic and emic perspectives in conducting such trials in India and seeks to generate an ethical coherence to the justification for conducting CHIM studies in India. The paper deliberates on ethical issues arising out of conducting CHIM studies and reflects on how developing the capacity for CHIM studies in India is likely to strengthen the health research and development sector in the country.

\section{Introduction}

The strength of any country's ethical research fabric lies in how and in what ways the scientific discourse benefits both the country's public health and scientific advancement. Clinical trial operations in India are not in alignment with her healthcare needs and have swerved away from infectious diseases like tuberculosis and malaria with an unfairly large proportion of registered trials focusing on non-communicable diseases like cancer and diabetes (1). This is despite the fact that the Global Burden of Disease Study for 2016 showed that communicable, maternal, neonatal and nutritional diseases (CMNNDs) contribute $24.8 \%$ of the overall disease burden

Author: Saumil Y Dholakia (dholakiasaumil@cmcvellore.ac.in), Professor, Department of Psychiatry, Christian Medical College, Vellore, Tamil Nadu 632 002 INDIA

To cite; Dholakia SY. Conducting controlled human infection model studies in India is an ethical obligation. Indian J Med Ethics. 2018 Oct-Dec;3(4) NS:279-85.DOI:10.20529/JME.2018.083

Published online on November 8, 2018

Manuscript editor:Vijayaprasad Gopichandran

Peer Reviewer:Vineeta Bal

OIndian Journal of Medical Ethics 2018 in India $(2,3)$. Infectious diseases in India have the highest Disability Adjusted Life Years (DALYs), but account for only $5 \%$ of the total clinical trials registered between July 2007 and December 2015. Interestingly, a large proportion (46.6\%) of these trials were phase III trials and only $6.5 \%$ were phase I trials (4).

The skew towards phase III trials may understandably weaken the pace of scientific and technological enhancement of the Indian scientific enterprise; phase III trials are, after all, trials which test already-tested drugs on a larger patient population, whereas phase I trials involve healthy human volunteers and hence require much more scientific expertise and ethical and regulatory preparedness (5). The safety of the participants who take part in these "first in man" studies is the combined social, moral and scientific responsibility of the research community.

Is the Indian scientific-ethical research fabric strong enough to bear the responsibility of such trials? As of now, legal and regulatory requirements allow trials involving healthy human volunteers only for testing indigenously developed drugs and patents or foreign drugs which are already tested or are being concomitantly tested in healthy human volunteers elsewhere (6). Against this background, this essay argues the scientific and ethical merits of a specific trial design which involves the introduction of specially developed attenuated strains of microorganisms into healthy human volunteers.

In order to understand the study design completely, the paper presents the definition and overview of a CHIM study design, discusses the uses of CHIM studies, and discusses the shift of focus from whether CHIM studies are ethically permitted or not, to CHIM studies being ethically required in India.

The paper goes on to present the inside (emic) and the outside (etic) perspectives on CHIM studies in India, and attempts to integrate both views to justify conducting CHIM studies in the country as a moral obligation, an ethical duty which is likely to benefit the public at large and the scientific community as a whole.

\section{Defining a CHIM trial: the what and how of a CHIM study design}

This section summarises some of the scientific, technical, and community-related issues involved in a CHIM study.

A typical Controlled Human Infection study model is a phase I trial involving the intentional introduction of a pathogen of public health importance, a pathogen whose pathogenesis is well understood, and which is administered through a known and standard route in a specific dose; and which does not 
cause any persistent infection or post-infection sequelae.Table 1 summarises the characteristics of an ideal pathogen strain for a CHIM study(7-11),

\section{Selection of subjects}

The well-standardised strain of pathogen in a CHIM study is introduced into carefully selected healthy, participant volunteers. These volunteers typically go through several stages of screening and are typically well-educated, wellnourished, young, healthy individuals with normal immune systems. The recruitment process should be able to answer the questions mentioned in Table 2(12-15).

\section{Safety considerations of participants}

Safety of the participant in a CHIM study is paramount and starts from the point of choosing the type of pathogenic strain used, to having stringent inclusion and exclusion criteria about volunteer participation, and rigorous screening measures for medical and psychological vulnerabilities. This can include a detailed vaccination history, review of past medical records and psychological assessments as per need. Table 3 summarises the various factors that need to be considered in order to ensure safety of the participants in a CHIM study(8,16-19).

\section{Why use challenge studies? Scientific merit of CHIM models}

Well-regulated challenge studies following universal scientific and ethical standards as described above have been a part of the scientific discourse of many countries for around 70 years now. More than 20,000 volunteers have taken part in around 143 trials in developed countries and 12 in low- and middleincome countries till date, and have contributed to answering important scientific and public health enquires as mentioned below:

\section{To understand and evaluate transmission of infection} CHIM study protocols have been developed to understand the transmission cycles of various pathogens inside the human body. A recent example is of a controlled human malaria infection model which studied gametocyte transmission of $P$ falciparum from humans to mosquitoes. This can have future implications in developing

\begin{tabular}{|l|l|}
\hline Table 1: Characteristics of a typical Controlled Human Infection Model-Pathogen strain \\
\hline Characteristics of an ideal pathogen strain for CHIM study. & Example of various pathogen strains used in CHIM studies. \\
\hline Needs to be of public health importance. & \\
\cline { 1 - 1 } Pathogenesis of the strain is well understood, including incubation \\
periods, course of illness, etc.
\end{tabular}

Table 2: Volunteer screening and selection in a typical CHIM study design:

\begin{tabular}{|l|l|}
\hline Questions & Points for reflection on relevance to Indian settings \\
\hline Is there fair selection of subjects? & $\begin{array}{l}\text { Social vulnerability in terms of poverty driving participation; } \\
\text { Competence vulnerability in terms of ability to understand } \\
\text { Inherent vulnerabilities of language, cultural differences and } \\
\text { Issues of family/individual consent. }\end{array}$ \\
\hline $\begin{array}{l}\text { Has the risk-benefit ratio been explained to and understood by the } \\
\text { proposed volunteers? Has a personalised risk-benefit statement been } \\
\text { made by the participant? }\end{array}$ & $\begin{array}{l}\text { Open discussion on risks, discomfort, lack of direct benefit, purpose of } \\
\text { enrollment, procedures involved including isolation (if involved), } \\
\text { Concept of individual risk vs tangible social benefit from the trial, and } \\
\text { Degree of compensation for risk vs harm involved in participation. }\end{array}$ \\
\hline Have efforts been made for community participation and engagement? & $\begin{array}{l}\text { Community sensitisation through focus group discussion platforms to } \\
\text { build transparency and accountability. }\end{array}$ \\
\hline Has the participant undergone a fair informed consent process? & $\begin{array}{l}\text { Adequate process for clarifications, freedom for refusal to participate, } \\
\text { confidentiality of information shared. }\end{array}$ \\
\hline
\end{tabular}




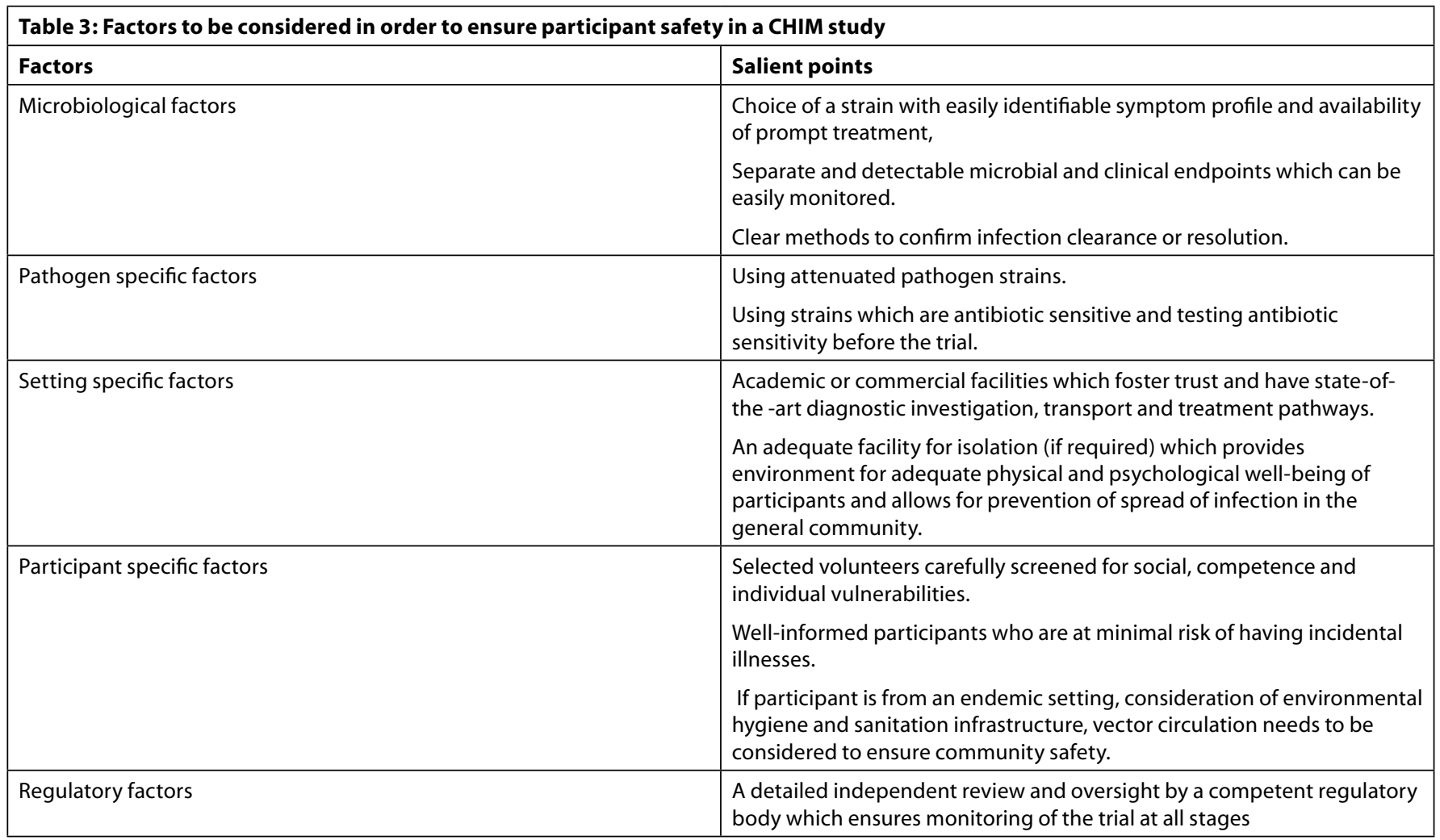

transmission-blocking interventions to prevent the spread of malaria (20).

2. To understand pathogenesis or human immune response to various pathogens

This is by far the most common use of challenge models. This is especially valuable for pathogens for which no suitable animal model exists. A good example would be the BCG human challenge model which provided important data on anti-mycobacterial immunity because of poorly understood animal data on immune responses to the same (21).

3. Use of CHIMs in vaccine studies

There has been growing interest in using challenge strains of micro-organisms to study vaccine efficacy by administrating these strains at some point in time after vaccination. These are essentially proof of concept trials which eventually help to fast-track vaccine development by checking its efficacy on smaller numbers of human volunteers and prevent unnecessary exposure of thousands of people in larger Phase III trials. One good example of the same is how an Indian Vi-tetanus toxoid conjugate vaccine developed by Bharat Biotech showed $87 \%$ efficacy in protection against typhoid fever in a phase Ilb randomised control study using a human challenge model by an Oxford Vaccine group in the United Kingdom $(22,23)$

4. Use in vaccine screening Challenge models are used to assess potential vaccine candidates before subsequent stages of development of the vaccine. This essentially means helping researchers to up-select or down-select potential vaccine candidates and thereby avoids large scale, expensive field testing of these vaccines. Examples of this include the use of radiation attenuated malaria vaccine using plasmodium sporozoites which can induce sterilising immunity against challenge models of infectious sporozoites in human volunteers (24)

\section{Use as therapeutic interventions}

Challenge models are used as direct therapeutic approach or aim to test the efficacy of a therapy after direct infection by a challenge strain. Examples of this include investigational therapeutics to treat shigellosis in various shigella flexneri models (25).

6. Use in dose escalation studies

Another area where challenge models are used is to determine challenge dosages needed to reach specific attack rates-example of this include salmonella typhi dose escalation studies in an ambulant model design to advance the understanding of host-pathogen interactions and immunity at different doses of exposure to salmonella typhi (26).

7. For study of various facets of infection and derived immunity in humans.

Human challenge studies are the most obvious way to prove causality. Unlike past self-challenge serendipitous discoveries, well regulated CHIM studies have been able to identify rhinovirus as the main cause behind the common cold. Another important area where CHIM studies have contributed is in knowing important virulence factors and 
identifying mechanisms underlying host susceptibility. An example of this is the $N$. Gonorrhoae $\operatorname{lgA} 1$ protease deficient strain challenge model which attempts to assess its potential virulence in male volunteers (27).

\section{Does India need CHIM studies? Emic and etic perspectives}

As is evident, CHIM studies are technically challenging and ethically demanding as they attempt to balance acceptable levels of risk to healthy human volunteers with a transparent and truly informed consent process. CHIM studies are also socially compelling as, though they do tend to answer questions of public health importance; they also demand community participation and sensitisation to the nebulous concept of risk-benefit ratios in research.

So, does India need such ambitious projects at all? Can't we do without them? Are CHIM studies a "want" or a "need" for Indian society? What is the social value of such studies in India?

An ethical enquiry into the need for CHIM studies in India would require one to use both emic and etic perspectives to understand the relevance of such studies in the Indian cultural fabric. The subsequent sub-section weighs conflicting prima facie obligations using the reflective equilibrium approach (28) to reach a state of balance justifying the conduct of CHIM studies as a moral obligation.

\section{What is the Reflective Equilibrium approach?}

Generating a coherent argument is central to moral justification. A principle, a theory or a judgement would become obligatory if (and only if) it has gone through a process which allows pruning, matching and adjusting of what John Rawls called "considered judgments". A considered judgement is one which is the starting point of an argument and is held with the highest confidence and with the least bias. For example, the moral axiom of "Research should benefit the participant" will start as a considered judgement in the design of a research proposal, However, this anchor will need to go through a process of specification and balancing; a process called reflective equilibrium to reach a state of harmony with the situation to render it coherent. In this example, the axiom will need to be made as coherent as possible with equally or more demanding considered judgements: the scientific need to pursue research, benefit to society, or respect for the autonomy to reject participation even if it is beneficial - just to name a few. The idea is that irrespective of what is finally opted for, the maximum coherence of norms will always be a primary objective.

Using this method, the next sub-section argues within the emic and etic dimensions of the Indian research fabric for CHIM studies becoming an obligatory need

\section{An emic perspective}

CHIM studies, from an emic (from the inside) perspective of an average healthy participant volunteer, would arouse serious doubts about the Indian ethical research fabric which need to be explained and resolved in order to reach a reasonable reflective equilibrium.

First and foremost, these studies challenge the established principle/considered judgement of primum non nocere"Above all, do no harm" and flood the average, informed Indian healthy volunteer's mind with appalling historical memories of unregulated scientific experiments performed by the Nazis, and the Tuskegee experiments on normal human subjects which would clearly be considered unethical today (29-30). The Indian research environment has seen turbulent times with reports of direct harm to uninformed vulnerable participants in the now infamous phase III trials conducted in Indore and Bhopal in 2004; and the human papillomavirus vaccine trials involving girls from tribal communities in Gujarat and Andhra Pradesh in 2010 (31-34).

However, the argument which sharpens the established principle is that the starting point of a CHIM trial is a wellinformed, healthy, adult volunteer who has clearly understood the risks involved in participation and is carefully selected through a transparent and accountable informed consent process; and not an individual vulnerable on account of social, individual or competence vulnerabilities. A robust informed consent process is an absolute necessity but may not be a sufficient pre-requisite for any phase I trial. The participant in a CHIM trial is also someone who has understood the known, unknown and potential risks involved and again, the engaging point is not an ill-defined or general risk expression; it is a clear, unambiguous communication of defined risk with respect to the concerned CHIM model. And as Evans and Evans have put it-"when research is avowedly non-therapeutic, we could say that the risks are minimal if the research procedure involves no foreseeable harms which are either more likely or more severe, than those that one could meet in everyday life. It is expected that daily life, involves a certain amount of risk, after all"(29). Of course, a CHIM trial cannot be called "nontherapeutic", but the statement provides a reference point of what could be considered minimal risk and which trials can be considered too dangerous to participate in. "Minimal risk" in research is thus the amount of risk which is no more harmful than the risk entailed in certain activities that an individual voluntarily takes part in in everyday life. This standard, if taken as the minimum standard for any Indian participant, will ensure maximum protection of the participant entering any trial. This assessment of risk, if considered as reference standard, allows a dimensional and subjective degree of minimal risk that the participant can be lawfully helped to take in their own comparable areas of life. This is obviously unlike the stance that most guidelines take with respect to allowable risk in research. However, this does provide a dimensional aspect to the categorical and certainly narrower construct of primum non nocere and allows a higher moral justification to be reached from the participant's point of view in case of CHIM trials.

Taking the sharpening process further-a well-informed healthy volunteer completely aware of the risks involved for 
participation in CHIM studies in India might be a necessary pre-requisite but may not be sufficient to justify a CHIM trial in India. A research participant anywhere around the world would consider the social value of any research at par with, if not above, the scientific rigour of the research design. Most of the diseases that challenge models investigate for pathogenesis, immunity, treatment or vaccines studies are endemic in India. From an emic perspective, CHIM studies in diseaseendemic settings like India provide a better understanding of genetics, pre-exposure, immune status and environmental factors that play a role in disease manifestation. The potential social benefits of generating evidence from a country's own population and for the benefit of their own society make ethical, social and political sense. For example, it would have been much more ethically justifiable if the evidence of efficacy of the typhoid vaccine in the recently concluded phase IIb trial had been tested on consenting healthy volunteers in an Indian setting for two reasons: first, typhoid is endemic in India and the results would have been generalisable to the Indian population; and second, the CHIM strain of Typhoid vaccine (Vi-TT, typbar-TCV) was developed in India. The "Of the participant, By the experts-participants joint endeavour, For the participant" argument makes the ethical justification much more coherent, inclusive and adds weight to CHIM studies becoming an obligatory need from an emic perspective.

\section{An etic perspective}

From an etic (from the outside) perspective, an important established principle/considered judgement to begin with would be that involving distributive justice: given the dramatic inequalities in access and exorbitant increases in the costs of healthcare, would it be fair and equitable for the scientific diaspora to invest limited resources in demanding trials like $\mathrm{CHIM}$ in a resource-poor country like India?

\section{Premise of fundamental need}

In order to answer this complex question-let us look into the concept of what constitutes a fundamental need. A fundamental need would be one which, if not provided/ distributed according to need, could result in the individual or community suffering harm, or at least a detrimental effect. Though the need for CHIM studies from a scientific perspective is clear, as aiding scientific development, it becomes an ethical obligation only when it resonates with the concept of a fundamental need.

\section{Argument towards a CHIM study being a fundamental need}

Using the reflective equilibrium approach, let us start with the established scientific principle that a controlled human infection model is beneficial for assessment of a preliminary vaccine or assessment of human immune response to a particular pathogen for a society which needs it. Suppose such a CHIM study is designed for a small population of healthy consenting volunteers and this shows that the candidate vaccine is ineffective; this in a way helps prevent a larger harm by avoiding the unnecessary exposure of thousands of people to large and costly phase III trials which would otherwise have to be designed to test its benefit. Having said this, it does not mean that human challenge trials are an alternative to phase III trials, they may help in licensing a product, which is then followed by strict post -marketing surveillance of the product-as is evident from the development of cholera vaccine Dukoral (35). Further, sharpening the established principle, using a CHIM design may prevent harm by avoiding exposure of the general population to vaccine candidates which are tested for efficacy in animal models, after all, animal models are often inadequate predictors of immune response.

The etic perspective on the issue of conflicting fundamental needs

Thus, providing an opportunity to participate in a $\mathrm{CHIM}$ trial to a healthy, consenting volunteer in India becomes a fundamental need based on a double negative argumentnot providing such an opportunity may amount to possible harm. This is obviously a weak argument, chiefly because this fundamental need has to compete with larger and often unfulfilled needs like basic sanitation and provision of primary healthcare facilities to the Indian population. It is obvious that the latter may be considered a higher priority over the former in Indian society where healthcare lacks insurance support and is starkly unequal in distribution. However, egalitarian principles of justice do further sharpen the original established principle with respect to CHIM studies: well equipped healthcare institutions should allow each person to achieve a fair share of the normal range of opportunities available in society. Among others, a CHIM trial is one such opportunity.

\section{Towards an integrated approach: Justifying CHIM studies in India}

Thus, based on the reflective equilibrium approach which sharpens established principles and considered judgments, both emic and etic perspectives seem to justify the idea of a CHIM study for the Indian population.

Justifying the act of conducting a CHIM study in India would require procedural justice and regulatory vigilance to be implemented at all steps of a CHIM study. Developing adequate infrastructure and clinical services which allow volunteer participants to be engaged outside their home environment for a stipulated time period, establishing laboratory facilities and infrastructure requirements for developing and regulating delivery pathways to locally relevant strains of pathogens under Good Manufacturing Practices guidelines seems to be the first procedural step towards conducting CHIM studies in India.

The second and equally important step would be to develop scientific rigour to structure protocols for a fair selection of participants and ensure a robust informed consent process. Community participation, transparent public engagement, assessment of motivation for participation and justified provision of compensation for the risk/harm for the participant provides a trust-building third step. 
Finally, ensuring and implementing regulatory policies for the safety of the volunteers participating in CHIM studies in India can be achieved through a robust regulatory environment supported by law, which meets and enforces high regulatory standards of care provided to the participants.

\section{Challenges and recommendations}

Prima facie obligations and prima facie rights always prevail, unless a competing moral obligation or right can be shown to be overriding in particular circumstances. As Ross puts it, "the greatest balance" of right over wrong must be found (28). This bioethical enquiry into the need for CHIM studies through emic and etic perspectives, using reflective equilibrium, does generate coherence to justify conducting $\mathrm{CHIM}$ studies in India as a moral obligation.

Notwithstanding the compelling scientific and ethical merits of the argument, the moral sense of necessity motivating people to participate and to act to fulfil local needs, supported by provision of a transparent and strong regulatory platform to conduct CHIMs where all stake-holders' interests are considered,with trust as a central ingredient in a common agenda to ensure safety of the participants remains the major challenge of this ethical discourse(36)

\section{References}

1. Mondal S, Abrol D. Clinical trials industry in India: A systematic review[Internet]. Working Paper 179. New Delhi: Institute for Studies in Industrial Development; 2015 Mar[cited 2018 Mar 13]. Available from: http://isid.org.in/pdf/WP179.pdf

2. Indian State-Level Disease Burden Initiative Collaborators. Nations within a nation: variations in epidemiological transition across the states of India, 1990-2016 in the Global Burden of Disease Study. Lancet. 2017 Dec 2;390(10111):2437-60.

3. Indian Council of Medical Research, Public Health Foundation of India, Institute for Health Metrics and Evaluation. India: Health of the Nation's States- The India State-Level Disease Burden Initiative. New Delhi:ICMR, $\mathrm{PHFl}$, and IHME;2017 [cited 2018 Mar 13]. Available from: http://www. healthdata.org/sites/default/files/files/policy_report/2017/India_ Health_of_the_Nation\%27s_States_Report_2017.pdf

4. Chaturvedi M, Gogtay NJ,Thatte UM. Do clinical trials conducted in India match its healthcare needs? An audit of the Clinical Trials Registry of India. Perspect Clin Res. 2017 Oct-Dec;8(4):172-5.

5. Ramkumar A. Early phase studies in India: Are we too early to explore? Indian J Pharmacol. 2008 Oct;40(5):189-90.

6. Sharma H, Parekh S. Clinical Trials Regulations in India. Pharm Regul Aff [Internet]. 2012 Nov 3 [cited 2018 Mar 14];1(4).e118. Available from: https://www.omicsonline.org/open-access/clinical-trials-regulationsin-india-2167-7689.1000e118.php?aid $=14913$

7. Porter CK, Louis Bourgeois A, Frenck RW, Prouty M, Maier N, Riddle MS. Developing and utilizing controlled human models of infection. Vaccine. 2017 Dec 14;35(49 Pt A):6813-8.

8. Darton TC, Blohmke CJ, Moorthy VS, Altmann DM, Hayden FG, Clutterbuck EA, Levine MM, Hill AV, Pollard AJ.. Design, recruitment, and microbiological considerations in human challenge studies. Lancet Infect Dis. 2015 Jul;15(7):840-51.

9. Shirley D-AT, McArthur MA. The utility of human challenge studies in vaccine development: lessons learned from cholera. Vaccine Dev Ther. 2011 Oct;2011(1):3-13.

10. Miura K. Progress and prospects for blood-stage malaria vaccines. Expert Rev Vaccines. 2016 Jun 2;15(6):765-81.

11. Feasey NA, Levine MM. Typhoid vaccine development with a human challenge model.Lancet.2017 Dec 2;390(10111):2419-21.

12. Bambery B, Selgelid M, Weijer C, Savulescu J, Pollard AJ. Ethical Criteria for Human Challenge Studies in Infectious Diseases: Table 1. Public Health Ethics. 2016 Apr;9(1):92-103.
13. Emerson $\mathrm{Cl}$. Ethical Considerations for Human Challenge Studies. London, UK; Academy of Medical Sciences;2018 Feb 6[cited 2018 Mar 18]. Available from: https://acmedsci.ac.uk/file-download/70768021

14. Chapman AR. Addressing the ethical challenges of first in-human trials. J Clin Res Bioeth [Internet]. 2011 Jul 10 [cited 2018 Mar 18];2(4):113. Available from: https://www.omicsonline.org/addressing-the-ethicalchallenges-of-first-in-human-trials-2155-9627.1000113.php?aid $=1550$

15. Gopichandran V. Controlled human infection models for vaccine development:Zika virus debate. Indian J Med Ethics [Internet]. 2018 JanMar [cited 2018 Mar 18];3(1):51-5. Available from:http://ijme.in/articles/ controlled-human-infection-models-for-vaccine-development-zikavirus-debate/?galley=html

16. Gordon SB, Rylance J, Luck A, Jambo K, Ferreira DM, Manda-Taylor L, et al. A framework for Controlled Human Infection Model (CHIM) studies in Malawi: Report of a Wellcome Trust workshop on CHIM in Low Income Countries held in Blantyre, Malawi. Wellcome Open Res. 2017 Aug 24;2:70.

17. Expert Committee on Biological Standardisation. Human Challenge Trials for Vaccine Development: regulatory considerations. Geneva; WHO; 2016 Oct[cited 2018 Mar 18]. Available from: http://www.who.int/ biologicals/expert_committee/Human_challenge_Trials_IK_final.pdf

18. Miller F G, Grady C. The ethical challenge of infection-inducing challenge experiments. Clin Infect Dis. 2001 Oct 1;33(7):1028-33.

19. Balasingam $S$, Horby $P$, Wilder-Smith $A$. The potential for a controlled human infection platform in Singapore. Singapore Med J. 2014 Sep;55(9):456-61.

20. Collins KA, Wang CY, Adams $M$, Mitchell $H$, Rampton $M$, Elliott $S$, Reuling IJ,Bousema T, Sauerwein R, Chalon S, Möhrle JJ,McCarthy JS. A controlled human malaria infection model enabling evaluation of transmissionblocking interventions.J Clin Invest. 2018 Apr 2; 128(4):1551-1562

21. Minassian AM, Satti I, Poulton ID, Meyer J, Hill AVS, McShane H. A human challenge Model for Mycobacterium tuberculosis using Mycobacterium bovis bacille Calmette-Guérin. J Infect Dis. 2012 Apr 1;205(7):1035-42.

22. Jin C, Gibani MM, Moore M, Juel HB, Jones E, Meiring J, Harris V, Gardner J, Nebykova A, Kerridge SA, Hill J, Thomaides-Brears H, Blohmke CJ, Yu LM, Angus B, Pollard AJ. Efficacy and immunogenicity of a Vi-tetanus toxoid conjugate vaccine in the prevention of typhoid fever using a controlled human infection model of Salmonella Typhi: a randomised controlled, phase $2 b$ trial. Lancet. 2017 Dec 2;390(10111):2472-80.

23. Sharma NC. Bharat Biotech says typhoid vaccine shown to be safe, effective in human trials [Internet]. http://www.livemint.com/. 2017 [cited 2018 Mar 18]. Available from: http://www.livemint.com/Industry/ EMOkFcZoSOkCBhvvWfbzKP/Bharat-Biotech-says-typhoid-vaccineshown-to-be-safe-effect.html

24. Roestenberg M, Mordmüller B, Ockenhouse C, Mo A, Yazdanbakhsh $M$, Kremsner PG. The frontline of controlled human malaria infections: A report from the controlled human infection models Workshop in Leiden University Medical Centre 5 May 2016. Vaccine. 2017 Dec 18;35(51):7065-9.

25. Mani S, Wierzba T, Walker RI.Status of vaccine research and development for Shigella. Vaccine. 2016 Jun 3;34(26):2887-94.

26. Waddington CS, Darton TC, Jones $C$, Haworth $K$, Peters $A$, John $T$, Thompson BA, Kerridge SA, Kingsley RA, Zhou L, Holt KE, Yu LM, Lockhart S, Farrar JJ, Sztein MB, Dougan G, Angus B, Levine MM, Pollard AJ. An outpatient, ambulant-design, controlled human infection model using escalating doses of Salmonella Typhi challenge delivered in sodium bicarbonate solution. Clin Infect Dis.. 2014 May 1;58(9):1230-40.

27. Hobbs MM, Sparling PF, Cohen MS, Shafer WM, Deal CD, Jerse AE. Experimental Gonococcal Infection in Male Volunteers: Cumulative Experience with Neisseria gonorrhoeae Strains FA1090 and MS11mkC. Front Microbiol [Internet]. 2011 May 31 [cited 2018 Mar 18];2: 123:Available from: https://www.ncbi.nlm.nih.gov/pmc/articles/ PMC3119411/

28. Beauchamp TL, Childress JF.Principles of biomedical ethics. 7th ed. New York: Oxford University Press; c2013.

29. Hope T, McMillan J. Challenge studies of human volunteers: ethical issues. J Med Ethics. 2004 Feb 1;30(1):110-6.

30. Wrigley A. Human experiments - the good, the bad, and the ugly [Internet]. The Conversation.com. 2015 June 8[cited 2016 Nov 27]. Available from: http://theconversation.com/human-experiments-thegood-the-bad-and-the-ugly-39876 
31. WHO | Clinical trials in India: ethical concerns [Internet]. WHO. Date unknown[cited 2018 Mar 18]. Available from: http://www.who.int/ bulletin/volumes/86/8/08-010808/en/

32. Politzer $M$, Krishnan V. The dark underbelly of India's clinical trials business [Internet]. http://www.livemint.com/.2012 Oct 11 [cited 2018 Mar 18]. Available from: http://www.livemint.com/Politics/ D0gBgwCn3huK72S06p8K5H/The-dark-underbelly-of-Indias-clinicaltrials-business.html

33. Sharma K.Deaths in a trial of the HPV vaccine.Indian JMed Ethics [Internet] 2012 Jul-Sep;7(3):143. [cited 2018 Mar 18]. Available from:http://ijme.in/ articles/deaths-in-a-trial-of-the-hpv-vaccine/?galley=html
34. Sharma K. The other half: uninformed consent. The Hindu [Internet] 2010 Apr 17 [cited 2018 Mar 18]; Available from: http://www.thehindu. com/opinion/columns/Kalpana_Sharma/The-Other-Half-Uninformedconsent/article16123576.ece

35. Lopez AL, Gonzales MLA, Aldaba JG, Nair GB. Killed oral cholera vaccines: history, development and implementation challenges. Ther Adv Vaccines. 2014 Sep;2(5):123 -36. doi: 10.1177/2051013614537819

36. Bijker EM, Sauerwein RW, Bijker WE. Controlled human malaria infection trials: How tandems of trust and control construct scientific knowledge. Soc Stud Sci. 2016 Feb1;46(1):56-86.

\section{The ethics of volunteer selection and compensation in Controlled Human Infection Models in India}

\section{ANURADHA ROSE}

\section{Abstract}

Controlled human infection model studies, or challenge studies, involve the intentional infection of a consenting healthy human volunteer with a virulent organism under controlled conditions Such studies differ from clinical trials in that though both involve healthy volunteers, in challenge studies the potential harm experienced by participants is intended, not merely potentially foreseen, as in clinical trials. Given the special nature of CHIM studies, careful consideration of participant selection and compensation is essential. This paper explores the ethical criteria for recruiting participants in such studies, their own possible motivation such as monetary payment or access to treatment and how that should not amount to an inducement. It also distinguishes between compensation as inducement and fair compensation for the possible contracting of an illness, isolation, loss of work and adverse effects, and indicates that more research on the subject needs to be done.

\section{Background}

Controlled human infection model (CHIM) studies (or challenge studies) involve the intentional infection of a consenting healthy human volunteer with a virulent organism under controlled conditions. CHIM studies differ from clinical trials in some important aspects. While healthy volunteers are recruited for participation in both phase 1 clinical trials and challenge studies, the anticipation of harms is different. In challenge studies potential harm experienced by participants is intended, not merely potentially foreseen, as in clinical

Author: Anuradha Rose (anurose@cmcvellore.ac.in), Professor, Department of Community Medicine, Christian Medical College, Vellore, Tamil Nadu 632 002 INDIA.

To cite: Rose A. The ethics of volunteer selection and compensation in Controlled Human Infection Models in India. Indian J Med Ethics.2018 OctDec;3(4) NS:285-9.DOI: 10.20529/JJME.2018.084.

Manuscript Editor:Vijayaprasad Gopichandran

Peer Reviewer: Manickam Ponnaiah

OIndian Journal of Medical Ethics 2018 trials that evaluate safety (1). The first report from participants in a malaria human challenge model in Kenya found that participants reported financial compensation as their major motivator for participation (2), which emphasises the special nature of ethical review and oversight of CHIM studies, requiring careful consideration of participant selection and compensation. However, the objectives of ethical review and oversight remain the same, and they are to ensure the wellbeing and prevention of exploitation of research participants (3).

The memories of unethical research from the Nazi regime and other historical research where participants have been exploited have made some of the public suspicious of any type of medical research $(4,5)$. These violations of ethics have made medical research the object of close scrutiny by the media, public and regulators, with violations paving the way for the development of guidelines, codes and regulations governing the conduct of research. However, even though CHIM studies have been conducted for several decades now outside of India, until recently there have been no ethical guidelines developed specifically for this type of research.

In spite of the existence and use of guidelines, and scrutiny of studies by institutional review boards (IRBs), research has not been without controversies in India. Deviations from guidelines, both old and new, continue to make media headlines. In the light of this milieu, how can researchers ensure ethical conduct of CHIM studies, whose very design has the potential to arouse negative public opinion and media attention?

An important ethical violation often highlighted is the criteria used for selection of participants in research. Critiques have pointed out several deviations from ethical selection including deception during recruitment (5), poor consenting processes, and inadequate disclosure of risks, incentives and compensation clouding a potential participant's judgement, subtle coercion, vulnerable participants being chosen for ease of conducting the study and to ensure consent (6) and so on. Inadequate knowledge of participants' motivation to 